\title{
An evaluation of the proposed ITS system for the city of São Paulo based on the 2015 tender
}

\author{
Mauricio Consulo ${ }^{1}$, Maria L. R. P. D. Scoton¹, Jilmar A. Tatto ${ }^{1}$, Eduardo M. Dias ${ }^{1}$ \\ ${ }^{1}$ GAESI -Grupo de Automação Elétrica em Sistemas Industriais, Escola Politécnica da Universidade de São Paulo, Av. Prof. Luciano \\ Gualberto, trav. 3, no 158, CEP 05508-970, São Paulo/SP, Brazil, http://www.gaesi.eng.br
}

\begin{abstract}
The Secretary of Transportation of the city of São Paulo recently released a public consultation for the city's Urban Mobility plan. This consultation is quite broad in scope, addressing many different areas of the bus public transportation modal in the city, including the operation itself, control and bus terminal administration. The proposal contains guidelines to reorganize the actual services using the infrastructure already deployed. This article will bring to light the development stages of the ITS in the United States, Europe, and Japan while focusing on the technology portion of the São Paulo tender such as: (i) planning and scheduling systems, (ii) operational control center and its technologies to monitor and control the operation, (iii) the on-board technologies, and (iv) the integration to the existing track and location (T\&L), control and reporting system called SIM - Sistema Integrado de Monitoramento (Integrated Monitoring System). The main goal of this article is to map the proposed ITS system for the city of São Paulo and compare it to the world class systems operating in the major cities in the world highlighting the areas of excellence and the ones with room for improvement.
\end{abstract}

\section{Introduction}

Nowadays, it is extremely difficult to decouple Intelligent Transportation Systems (ITS) from the concept of smart cities. The major cities around the world are addressing the Urban Mobility as a key component of their planning and governance. Most cities worldwide were not built with the vision for expansion, such as new streets and avenues, bus lanes, or Bus Rapid Transit (BRT). As a result, even the construction of monorails and subways lines can be onerous and inefficient due to the need to renovate overall infrastructures around these cities in order to accommodate new public transportation options. For example, streets in the downtown area of many cities in Latin America are narrow and contain landmark buildings, which restricts construction area wise as well as in capital.

A balance of construction and technology needs to be achieved. However, in the Latin American scenario the technology and the intelligent transportation systems play a more important role in this equation and both necessary to improve road network capacity. The correct use of technology can boost the correlation of the road network, bus lanes, BRT and its clients. As a result, the ITS systems can become more data driven, making the traffic management system more efficient, convenient, safe and reliable.

ITS provides the ability to gather, organize, analyze, use, and share information about transportation systems and it can be used by decision makers and planners in order to increase their awareness of the benefits as well as the prerequisites of ITS. Its ability is decisive and effectual for the economical construction and operation of transportation systems and to their efficient use.

\section{Outlook of ITS in the U.S.A, Europe and Japan}

The fundamental reasons for introducing ITS are similar in many countries across the world. Numerous governments are seeking to increase efficiency, safety and to reduce the environmental impact.

The ITS deployment was led by United States of America, Europe and Japan. The incentive for these regions has many similarities, including the economical interest supported by technology, the need to expand the transportation systems, and a coordinated effort between the industry, government, and academia.

\subsection{United States of America}

In the United States of America (U.S.A.), the ITS systems began with the electronic route guidance system (ERGS) in 1967 [2] from a study performed by the Bureau of Public Roads of the US Department of Transportation (USDOT). ITS started to become an important part of major highway transportation laws. Later, in 1991, the USDOT included the Intermodal Surface Transportation Efficiency Act (ISTEA, 1991)

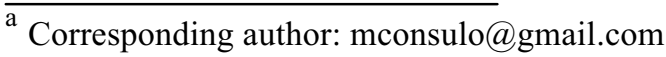


and the Transportation Equity Act for the 21st Century (TEA-21, 1998).

In 1997, the Intelligent Vehicle Initiative (IVI) had its debut by the USDOT, "this initiative aims to accelerate the development, availability, and use of integrated invehicle systems that help drivers of cars, trucks, and buses operate more safely and effectively" [3]. Afterward, the Vehicle Infrastructure Integration (VII) project [4] was proposed. The main goal of this project was to provide a standardized communication channel between the physical surroundings and the vehicles on the road in order to improve safety. Another US program, called Cooperative Vehicle-Highway Automation Systems (CVHAS) [5], is also supported by the US federal pooled fund program and has focus on improving the safety, mobility, and other essential concerns, followed the VII.

The "ITS Joint Program Office (ITS JPO), within the Office of the Assistance Secretary for Research and Technology (OST-R), is in charge of executing the Subtitle C- Intelligent Transportation System Research of Public Law 109-59 - Safe Accountable, Flexible, Efficient Transportation Equity Act: A Legacy for Users, enacted August 10, 2005, which requires the Department to: Conduct an ongoing intelligent transportation system program to research, develop, and operationally test intelligent transportation systems and to provide technical assistance in the nationwide application of those systems as a component of the surface transportation systems of the United States"[6].

The USDOT has a complete and comprehensive Intelligent Transportation Systems (ITS) strategy plan for 2015 to 2019. This "plan is built on the success of the 2010 to 2014 plan and presents a wide array of technical, policy, institutional, and organizational concepts. It provides a comprehensive perspective that is based on an inclusive, collaborative, interactive, and iterative process, with a wide mix of stakeholder engagement opportunities that ensured that the Strategic Plan reflects the aspirations of the multi-faceted ITS community across the nation." [7]. For the next four years, this proposal has a clear vision to "transform the way society moves". This is a very bold foresight, which reflects the American pragmatism, and the way they organize their future. This vision is supported by two primary strategies: (i) Realizing Connected Vehicle (CV) Implementation and (ii) Advancing Automation.

These two primary strategies are supported by the following themes adopted by the USDOT as priorities:

- enable Safer Vehicles and Roadaways;

- enhance mobility;

- limit Environmental Impacts;

- promote Innovation; and

- Support Transportation Systems Information Sharing.

A more comprehensive and complete study about the USDOT Intelligent Transportation Systems (ITS) strategy plan for 2015 to 2019 is the subject for a future article. The objective of this session is to illustrate the state of development and planning of the ITS systems in the United States of America.

\subsection{Europe}

The ITS systems had its genesis back in the early 1970s, and one of the first projects was the Road Transport Informatics (RTI) [8]. Other projects such as the Dedicated Road Infrastructure for Vehicle Safety in Europe (DRIVE) [9] also took place in the 80s. In 1991, the EU launched its European Road Transport Telematics Implementation Coordination Organization (ERTICO) to promote ITS development. eSafety [10] is a representative program under ERTICO that aims to provide vehicle-based intelligent safety systems to improve road safety.

Europe plays a very active role in the regional and international ITS activities to advance its ITS, specially with the standards. "The European Committee for Standardization (Comité Européen de Normalisation CEN) has a technical committee (TC278 - Road Traffic and Transport Telematics) focused on ITS standards issues. TC278 works in close cooperation with the ITS Technical Committee (TC204) of ISO. Many ITS standards items are developed in parallel by ISO/TC204 and CEN/TC278" [11].

[11] also states that "Europe has been very successful in establishing partnerships" to conduct tests and demonstrations among European national and city governments, vehicle manufacturers and suppliers, and universities. Europe has also succeeded in establishing a robust industry for ITS infrastructure systems and enduser products, with customers worldwide".

\subsection{Japan}

Like Europe, Japan started its ITS efforts in the 1970s. At the time, the ITS research was to build a safe, ecofriendly, transport system. In 1998, an ITS application named Vehicle Information and Communication System (VICS) [12] was deployed to collect traffic information and deliver it to drivers. Japan's complex and congested road system has made this program particularly attractive to the driving public.

In the early 21 st century, Japan started a national program called Smartway [13] to promote Japan's ITS development. The promotion of ITS in Japan today is led by four Ministries and Agencies. The National position on ITS promotion was laid down in 1995 in the "Basic Guidelines on the Promotion of an Advanced Information and Telecommunications Society." [11]

Also, "Japan recognizes ITS as an opportunity to advance its industrial and trade interests, as well as a means to improve domestic transportation. Japan pursues international ITS standardization with a view to encourage international competition and safeguarding Japan's competitive position." [11]

It is interesting to see that each region has its goals and approach in the use and deployment of ITS. This analysis will be helpful to build a parallel with the project has been developed and implemented in Europe, U.S.A and Japan versus in Latin America, more specifically São Paulo, Brazil. 


\section{Urban mobility in Brazil}

Brazil, as many other countries in Latin America, does not have a national plan or strategy for ITS. Many different cities in Brazil, particularly the capitals, are building their own ITS tenders without a clear direction from the government. The Agência Nacional de Transportes Terrestres (ANTT - National Land Transportation Agency) has started initiatives, however, they are geared towards infrastructure and not technology. The Agência Nacional de Transportes Urbanos ANTU - National Urban Transport Agency) has a more technological focus and has released a publication entitled: "The best practices for the new Urban Mobility". Both agencies are working towards creating best practices and guidelines for the development Urban Mobility in Brazil.

In 2012, Brazil issued a federal law addressing Urban Mobility, Federal Law 12.587/2012. According to this law, the municipalities have until the end of 2015 to prepare and submit their Urban Mobility plan.

This Urban Mobility law has some key points as follow [14]:

- the prioritization of public transportation over private transportation projects and the drivers for integrated urban development;

- fare policy must have a contribution of direct and indirect beneficiaries to fund service operations;

- the pay rate is determined by the price (public rate) charged to the user plus revenue from other sources of funding

- the fare adjustments and revisions of the parameters used in the calculation will have the frequency established by the government in the announcement and in the concession for granting the service

- it is permitted to subsidize bus fares, which should be covered by non-ticket revenue, alternative revenues, budgetary or cross subsidies, intra sectorial and inter-sectorial subsidies.;

- the government is required to disclose in a systematic and regular basis the impact in the allowance in the fare paid by the user;

- the Federal, State and Local governments, and the Federal District have an obligation to contest the illegal transport of passengers and may sign agreements for this purpose;

- the government may establish restrictions, access control, temporary or permanent entry of motorized vehicles in certain locations;

- exclusive spaces on public roads for public transportation of passengers;

- companies may provide discounted fares, including seasonal promotions;

- surveillance of public transport services should be held preferably in conjunction with the federal and state governments.

Brazil has a government program called PAC that stands for Programa de Aceleração de Crescimento (Growth Acceleration Program) in which the Urban Mobility plans must be submitted. The PAC was created in 2007, during President Lula's second term (2007-
2010). PAC promoted the resumption of the planning and execution of social projects, as well as projects related to urban infrastructure, logistics and energy, contributing to its growth and sustainable development [15]. In addition, PAC has allocated R\$ 22.4 Billion Reals for Urban Mobility in the large cities of Brazil and R\$ 7 billion Reals for the mid size cities. Brazil has 75 municipalities that are eligible to receive the funds of PAC, in which 71 have already requested the funds for their projects. These 71 municipalities serve nearly 27 million inhabitants and are concentrated mainly on the southeast region Brazil along the coast [16].

Also, according to [14], Brazil has 107.000 buses with an average age of 4.2 years and 1.800 private bus operators. These private bus operators are responsible for 537.000 direct jobs, and their buses transport close to 40 million passengers daily in 3.311 cities that have an established bus transportation system. In Brazil, the buses are responsible for $86.8 \%$ of the passengers transported via mass transportation systems and $85.2 \%$ of the municipalities with more than 100 thousand inhabitants have electronic fair collection systems.

It is safe to say that Brazil is a highly dependable country on the modal bus as a mass transportation system, even though the number of users has declined drastically from the 1990s [17] due to some incentives and an increase in line of credit allowing more people to purchase cars. The Fig. 1 shows the decline of the passengers transported per month.

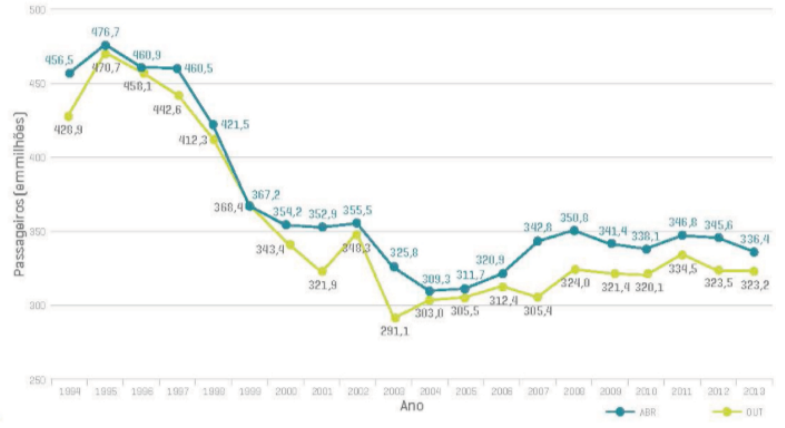

Figure 1. Passengers transported per month 1.

The above numbers are concerning when compared to Figure 2, which demonstrates that the distance covered per month is about the same as it was back in the 1990s, while the number of passengers was much higher than in the 2010s [17].

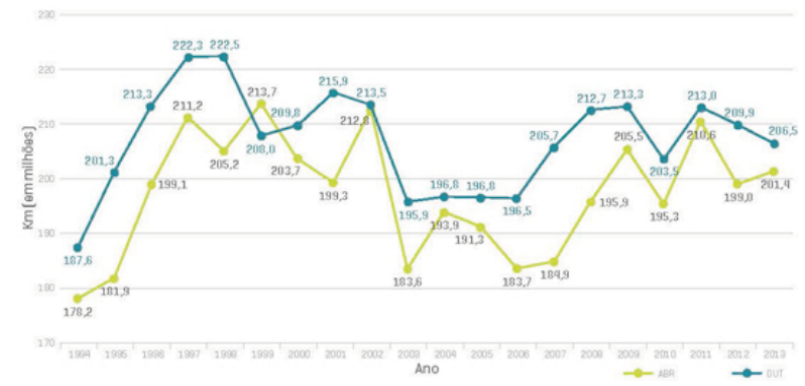

Figure 2. Km covered per month.

Fig. 3 demonstrates that the cost of fuel has also increased when compared to the 1990s [17]. 


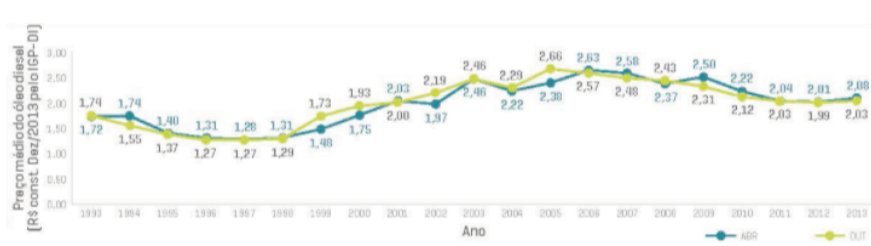

Figure 3. Cost of fuel.

Using these three elements: (i) passengers transported per month, (ii) $\mathrm{Km}$ covered per month, and (iii) the cost of fuel, one can infer that in order to be competitive and profitable, the private bus operators must find new ways to cut costs and operational inefficiencies. Intelligent Transportation Systems, including infrastructure and technology, have been presented as a possibility to the bus operators to optimize their operations and to become more efficient. The next session of this article briefly describes benefits that are brought by infrastructure innovations.

\section{The mass transportation system in São Paulo}

The city of São Paulo and its metropolitan area (39 municipalities) are home for 21 million people within an area of $8.000 \mathrm{~km} 2$. The Empresa Metropolitana de Transporte Urbano (EMTU), by Companhia Paulista de Trens Metropolitanos (CPTM), feeds the mass transportation system of São Paulo city and Companhia do Metropolitano de São Paulo (METRÔ). The city of São Paulo itself has São Paulo Transportes S.A. (SPTRANS) as its Transit Authority. The buses in São Paulo city cover more than $17 \mathrm{~km}$ of routes and in 10 rapid bus lanes with $110 \mathrm{~km}$ of extension, in which Expresso Tiradentes is the only one with the BRT characteristics. São Paulo has 28 bus terminals, 1500 routes, and 19 thousand bus stops serving 9 million passengers per day. Customers can use the SPTRANS, CPTM and METRÔ systems with just one fare card know as Bilhete Único (BU). Figure 4 shows the rapid bus lanes in São Paulo and Figure 5 demonstrates the subway system [18].

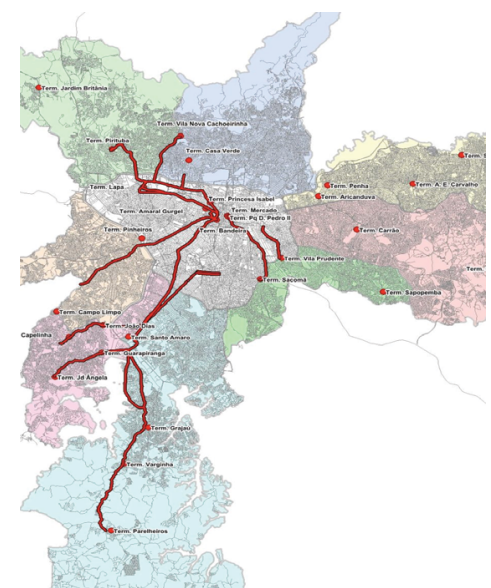

Figure 4. Bus Rapid Lanes in São Paulo

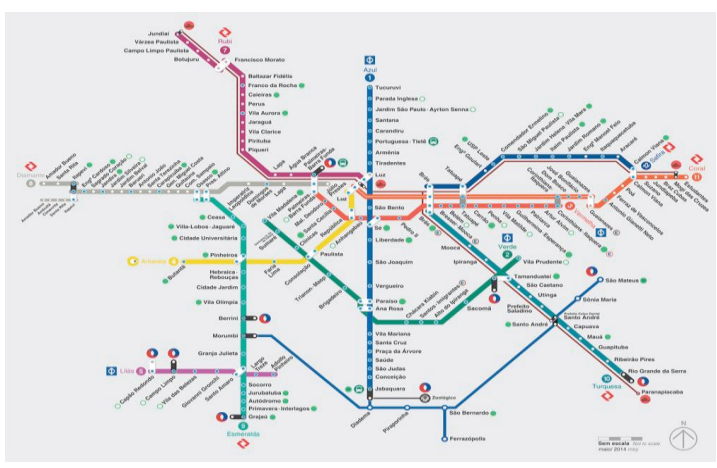

Figure 5. Subway system in São Paulo

\subsection{A bus lane implementation and results in São Paulo}

An ITS project consists of many different components, including civil construction, vehicles, sensors, on-board technology, command centers and personnel, just to list a few. In São Paulo, Companhia de Engenharia de Tráfego - CET [19] developed a project to create Bus Lanes (BL) in the city, and since the beginning more than $479 \mathrm{~km}$ of Bus Lanes were deployed in the city of São Paulo. The creation of Bus Lanes on the right side of the streets generated positive results to the modal bus, and consequently to the population. In 2013, CET reported a decrease in the total time travelled by bus in São Paulo decreased 38 minutes per day. Conversely, in 2014 this number increased to 40.7 minutes per day while the fuel consumption decreased by $8.8 \%$.

Before the Bus Lanes deployed in 2014, the average speed on the route was $12.1 \mathrm{~km} / \mathrm{h}$. After the implementation of the Bus Lanes, the average speed jumped to $20.3 \mathrm{~km} / \mathrm{h}$, an improvement of $67.5 \%$. The following routes have shown the most significant improvements:

- Best performance - Av. Jaguaré

- average speed jumped from $10.8 \mathrm{~km} / \mathrm{h}$ to $44.9 \mathrm{~km} / \mathrm{h}$; an improvement of $317.3 \%$;

- this Bus Lane has 12 routes transports 50.508 passengers per day, and serves 52 buses per hour during peak hours.

- Highlight - av. Belmira Marim - average speed increased from $9.5 \mathrm{~km} / \mathrm{h}$ to 25.2 $\mathrm{km} / \mathrm{h}$, an improvement of $165.7 \%$;

- this Bus Lane has 23 routes, transports 202.000 passengers per day, and serves 159 buses per hour during the peak hours.

- Largest extension - Av. Vila EMA/ Rua do Orfanato

- 2.5km of Bus Lane

- average speed leaped from $12.2 \mathrm{~km} / \mathrm{h}$ to 21.4 $\mathrm{km} / \mathrm{h}$;

- this Bus Lane has 6 routes, transports 77.031 passengers per day, and serves 56 buses per hour during the peak hours.

The overall average speed of the city of São Paulo went from $14.3 \mathrm{~km} / \mathrm{h}$ before the Bus Lanes, to an astounding $20.3 \mathrm{~km} / \mathrm{h}$ after Bus Lanes were adopted. This represents a $42 \%$ improvement in speed. The Bus Lanes 
also helped decrease the sluggishness of the city of São Paulo as shown in table 1.

Table 1. Decrease in sluggishness.

\begin{tabular}{|c|c|c|}
\hline Year & $\mathbf{K m} / \mathbf{h}$ & \% \\
\hline 2011 & 115 & - \\
\hline 2012 & 132 & 14,8 \\
\hline 2013 & 142 & 7,8 \\
\hline 2014 & 146 & 2,8 \\
\hline
\end{tabular}

As previously mentioned, civil construction in the cities is limited, and therefore, major improvements are difficult. In order to achieve a quantum leap in the transportation system, more advanced technology is necessary to better support the ITS initiatives, such as the Bus Lanes in São Paulo.

\section{Actual ITS system for the city of São Paulo}

According to [18], São Paulo's focus on ITS started in 1976 with the creation of Companhia de Engenharia de Tráfego (CET). In 1995, SPTRANS was created. In 2001, Municipal Law 13.241 organized the mass transportation system in the city. In 2004, Electronica fare collection was deployed in the city with Bilhete Único, initially using a magnetic strip followed thereafter by modern touch-less technologies. By 2005, the BU was also accepted by the CPTM and the METRÔ. The next big leap happened in 2008, with the implementation of the Sistema Integrado de Monitoramento (SIM), an integrated monitoring system using Automatic Vehicle Location (AVL) technology to track and locate the buses throughout the city. With the AVL technology, it was also possible to deploy LED signs in bus terminals and bus stops for Real Time Passenger Information (RTPI).

The creation of a Portal to provide RTPI and work as a channel of communication with SPTRANS and its customers. The SIM is outdated, therefore, a modernization request has been made in the new tender released for São Paulo's ITS system.

\subsection{Sistema Integrado de Monitoramento (SIM)}

Per [18], SIM is an integrated management system designed to monitor, control and supervise the quality of the service offered to the population. It collects and provides real time information about the buses, bus terminals to passengers and other systems. SIM has six subsystems, as follow:

- Integrated Control Center (ICC);

- Bus Terminal Operation Center (BTOC);

- Intelligent Bus Lanes (IBL);

- Concessionaires Operational Centers (COC);

- Fleet Management (FM); and

- On-board equipment a.k.a AVL (AVL).
The figure 6 shows the integration among the INFOTRANS (databases) and the SIM.

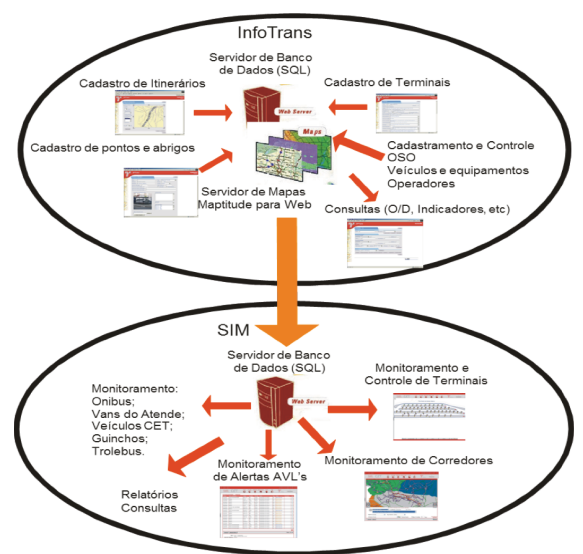

Figure 6. SIM and INFOTRANS Integration

As previously stated, the SIM system is outdated and the same is true for the on-board system that supports it. One out of the two hardware suppliers for the city of São Paulo is no longer providing any support to the on-board devices. This alone substantiates a great challenge for the bus operators to keep the system running and avoid the substantial penalties placed by SPTRANS when their buses are not communicating with the main bus system. Figure 7 shows the on-board equipment that is currently running in São Paulo's buses.

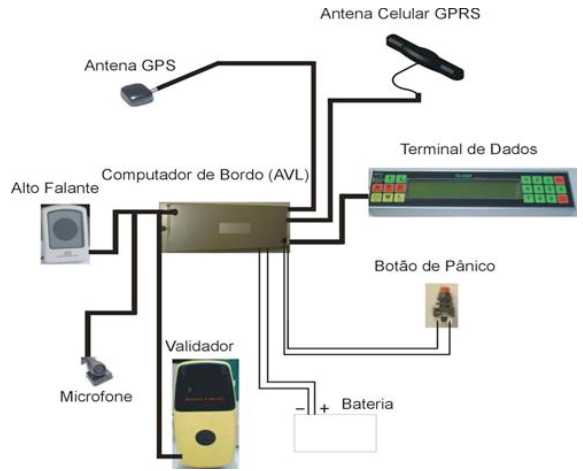

Figure 7. Actual O-Board equipment

The bus terminals have a Closed Circuit Television (CCTV) as shown on the figure 8 .

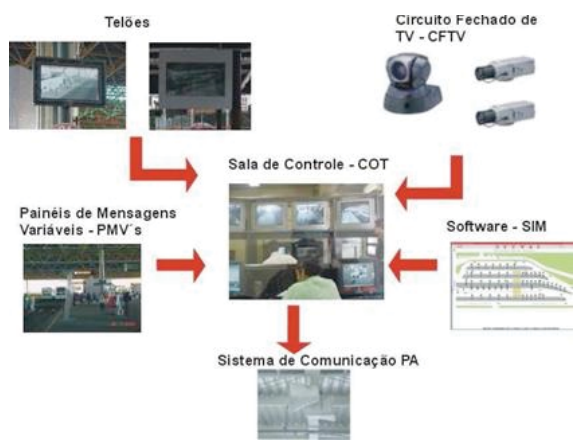

Figure 8. Bus Terminal Technology

The bus terminals are equipped with a CCTV, LED signs and LCD monitors for RTPI, a PA system and a 
SIM client. Even though the RTPI prediction is set for two minutes, there are many discrepancies in the accuracy due to the outdated on-board technology, which can be seen at the terminals and bus stops with the system. Another point of consideration is the fact that the analysis of the cameras is entirely done by people and lack intelligent systems, such as face recognition and pattern analyses.

SIM is not a system designed to take action, but rather to supervise and report. For example, there is no feature or functionality to self-regulate the operation. SPTRANS plays a passive role in the system and most of the bus garages have their own Operational Command Center (OCC) to monitor operation; SPTRANS only receives and consolidates the data.

Communication is another obstacle with the actual system. There is no VOIP implemented, preventing effective communication with the bus drivers. When the OCC attempts to contact a bus driver, the system stops providing real time bus location, prioritizing voice communication. Additionally, the command to restore the location of the bus does not work, asking for human intervention. As observed, communication with the bus drivers is done via Nextel radio or cellular phone.

Not all the reports are real time in SIM and most of the information is $\mathrm{D}+1$. The other concern is system reliability, which as been a recurrent complaint.

\section{Proposed new ITS sytems to the city of São Paulo}

Annex 7-A of the tender for São Paulo [18] brings on item 7.1.6, which include the following goals for the new ITS system for the city of São Paulo: (i) to renew the entire on-board system of the bus fleet in São Paulo, (ii) the adoption of a planning and scheduling system, a dispatching system, the construction of an Operational Control Center, and (iii) the deployment of all the hardware, software, data center and communication infrastructure.

The Operational Command Center (OCC) will have an area greater than $8.000 \mathrm{~m} 2$ where it will host the servers, links and the entire infrastructure necessary for the operation. It is also important to mention that the OCC will interface with other entities related directly or indirectly with the transportation system in São Paulo, such as: CET, Sistema de Atendimento Móvel de Urgência (SAMU), First Responders, Police, Fire Department among others.

Item 7.2.1.1 [18] describes the on-board architecture for the new ITS system of São Paulo as seen on the Fig. 9.

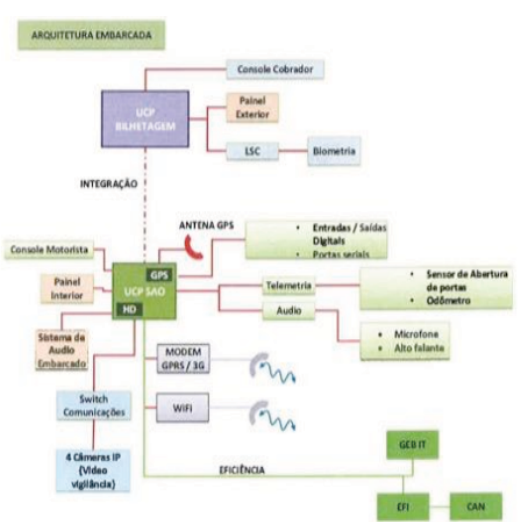

Figure 9. On-board architecture

The proposed on-board architecture is considerably more advanced and brings substantial enhancements when compared to the current deployed system (Fig. 7). The first and the most important difference is that the new system uses an on-board computer rather than a tracking device. This on-board computer brings the possibility to embed systems and bring intelligence to the bus, which will control other sub-systems, such as the internal passenger's information, public WiFi, VOIP, CCTV, emergency alarm, ticketing, Automatic Passenger Counting systems (APC) and telematics.

The specification is a high level solution, and escalates the ITS requirements for São Paulo to a world class system. From the big picture perspective, this tender follows the organization of the model proposed on [20], in which Stage 1 describes the benefits and motivations, and Stage 2 portrays the ITS applications and requirements. However, its limitation lies on the evaluation and implementation of the ITS system, shown below in Fig. 10.

Figure 10. Selection process

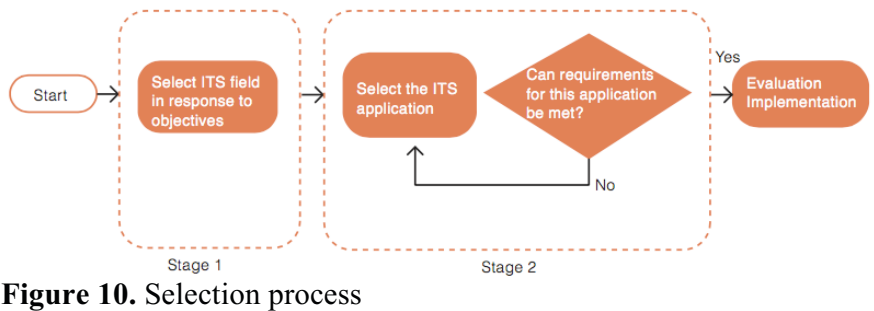

For example, decoupling the on-board computer from the software seems to be a great solution when you consider that the current fleet of São Paulo has close to 15.000 buses [18]. The possibility of choosing the onboard hardware empowers the bus operators to choose the technology that best fits their operation needs. In order to guarantee the integration among the different hardware platforms, SPTRANS created a certification process to guarantee that the hardware will meet the minimum requirements. This certification process is divided into three phases: (i) Documentation analysis, (ii) bench tests for hardware and software and (iii) the SIM integration. This is brings some complexity to the solution, regarding interoperability, but offers rubusticity when it comes to the on board certification process and all the international standards that must be followed. 
It is yet necessary to define the rules and standards when it comes to ITS functionalities and processes. That will be of great use in terms of interoperability.

Another proposition worth of highlighting in this tender includes the creation of a gateway to guarantee the communication of all CPUs, the current SIM system, and the future OCC software as see in Fig.11.

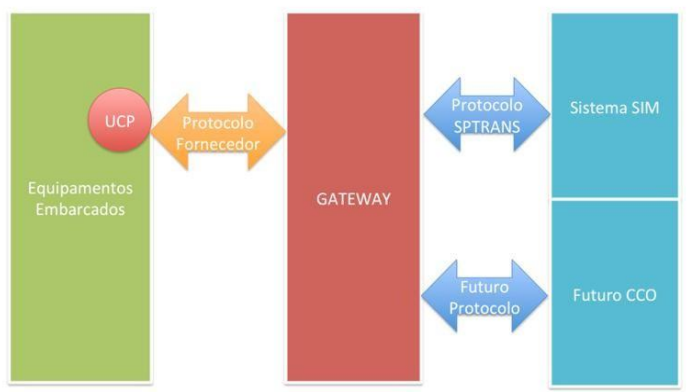

Figure 11. Selection process

This proposition is totally in line with open standards and will created mechanisms to foster a better interaction among the different on-board hardware. This gateway still does not solve the hardware/software compatibility issue described before but it is a step forward in terms of integration and open standards.

\section{Conclusion}

The tender released in São Paulo is an initiative to improve the chaotic traffic of the city and the metropolitan area. The changes in the civil infrastructure of the roads have already brought benefits to the city. These changes alone cannot produce additional benefits, so the need for the technology becomes apparent. São Paulo's tender demonstrated a regional action to update its on-board system and mimic the state-of-the-art ITS system in the world. This tender was a first step towards São Paulo ITS modernization. A great benefit was the development of a gateway to guarantee the communication of the SIM and the future OCC, favouring open standards. However, modernization is an on going process, so the work needs to evolve and approach other defying questions, like interoperability and description of features and functionalities.

Thinking country wise, Brazil would benefit from having a national plan or strategy for ITS, as do developed countries.

\section{References}

1. D. A. Rosen, F. J. Mammano, R. Favout, An electronic route-guidance system for highway vehicles. IEEE Trans Veh Technol, 19, 143-152 (1970)

2. C. Little, The intelligent vehicle initiative: advancing "human-centered" smart vehicles. Public Roads, 61 (1997). http://www.fhwa.dot.gov/publications/publicroads/9 7septoct/p97sept18.cfm

3. Intelligent Vehicle Initiative: Strategic Planning Overview, Draft, (1997).

4. R. Kandarpa, M. Chenzaie, J. Anderson, Final Report: Vehicle Infrastructure Integration Proof-ofConcept Results and Findings. C Infrastructure. Technical Report FHWA-JPO-09-057 (2009).

5. Y. F. Yin, M. A. Miller, S. E. Shladover, Assessment of the applicability of cooperative vehicle-highway automation systems to freight movement in Chicago. In: The 83rd TRB Annual Meeting, Washington, DC (2004).

6. US Department of Transportations: http://www.its.dot.gov/its_program/about_its.htm

7. US Department of Transportation: http://www.its.dot.gov/strategicplan.pdf

8. I. Catling, B. McQueen. Road transport informatics in Europe-major programs and demonstrations. IEEE Trans Veh Technol, 40, 132-140 (1991).

9. Oxley P R, Mitchell C G B. Final report on elderly and disabled drivers information telematics. R \& D Programme Telematics System in the Area of Transport (DRIVE II), Commission of the European Communities CEC, Brussels ( 1995).

10. A. Carrotta (ERTICO). Report on the Progress of the 28 eSafety Recommendations. Brussels (2008).

11. T. Yokota, ITS Technical Note for Developing Countries - Technical Note 1, NRI.

12. T. Tanaka, T. Yamamoto, S. Fukuda. Onboard system devices for a vehicle information and communication system. FUJITSU TEN Tech J, 7, 26-34 (1995).

13. T. Bar, D. Nienhuser, R. Kohlhaas, Probabilistic driving style determination by means of a situation based analysis of the vehicle data. In: The 14th International IEEE Conference on Intelligent Transportation Systems, Washington, DC, 16981703 (2011).

14. NTU - Dados do transporte público: http://www.ntu.org.br/novo/AreasInternas.aspx?idAr ea $=7 \&$ idSegundoNivel $=18$

15. Ministério do Planejamento: http://www.pac.gov.br/sobre-o-pac

16. Critérios técnicos na seleção de projetos. Apresentado pela SEMOB / Ministério das cidades: http:/thecityfixbrasil.com/files/2012/11/8CRITÉRIO S-DE-SELEÇÃO-DE-PROJETOS_SEMOB.pdf

17. NTU - Indicadores de desenpenho: http://www.ntu.org.br/novo/ListaDadosPorRegiao.as px?idArea $=7 \&$ idSegundoNivel $=17$

18. SPTRANS: http://www.sptrans.com.br

19. Companhia de Engenharia de Tráfego: http://www.cetsp.com.br/consultas/da-licenca-parao-onibus/o-programa.aspx\#

20. T. Yokota, Two stage Selection Model for ITS Applications- Technical Note 2, NRI.

21. 2015-2019 DoT Strategic Plan www.its.dot.gov 